\title{
A drug-coated balloon treatment for urethral stricture disease: Interim results from the ROBUST I study
}

Ramon Virasoro ${ }^{1}$; Jessica M. DeLong ${ }^{1}$; Rachel A. Mann²; Rafael E. Estrella ${ }^{3}$; Merycarla Pichardo ${ }^{4}$; Ramon Rodriguez Lay ${ }^{5}$; Gustavo Espino ${ }^{6}$; Joshua D. Roth ${ }^{2}$; Sean P. Elliott ${ }^{2}$ ${ }^{1}$ Department of Urology, Eastern Virginia Medical School, Norfolk, VA, United States; ${ }^{2}$ Department of Urology, University of Minnesota, Minneapolis, MN, United States; ${ }^{3} \mathrm{Clinica}$ Union Medica, Santiago de los Caballeros, Dominican Republic; ${ }^{4}$ URUS, Santo Domingo, Dominican Republic; ${ }^{5}$ Cirujano Urology Royal Center Panama City, Panama; ${ }^{6}$ Centro Especializado San Fernando, Panama City, Panama

Funding: This study was supported by Urotronic.

Cite as: Can Urol Assoc J 2020 January 20; Epub ahead of print. http://dx.doi.org/10.5489/cuaj.6323

Published online January 20, 2020

$* * *$

\section{Abstract}

Introduction: We aimed to investigate the safety and preliminary efficacy of the Optilume $\mathrm{T}^{\mathrm{TM}}$ paclitaxel-coated balloon for the treatment of recurrent urethral stricture.

Methods: Men with bulbar urethral strictures $\leq 2 \mathrm{~cm}$ with 1-4 prior endoscopic treatments were enrolled at four study sites after Ethics Committee approvals. All subjects were treated with mechanical balloon dilation or direct visualization internal urethrotomy prior to drug-coated balloon treatment. Patients were evaluated at 2-5 days, 14 days, three, six, and 12-months posttreatment. The primary safety endpoint was serious complications through 90 days postprocedure. The preliminary efficacy endpoint was anatomic success, defined as urethral lumen $\geq 14$ Fr at 12 months.

Results: A total of 53 subjects were enrolled and treated; 46 completed the 12-month followup. Forty-three percent of men had undergone $>1$ previous dilation; the mean for the overall study population was 1.7 prior dilations. There were no serious adverse events related to the treatment within 90 days. Anatomic success was achieved in 32/46 (70\%; 95\% confidence interval [CI] 54-82\%) at 12 months. The 14 failures included seven cystoscopic recurrences, five retreatments, and two patients who exited the study early due to symptom recurrence.

Conclusions: One-year data indicates the Optilume ${ }^{\mathrm{TM}}$ paclitaxel-coated balloon is safe for the treatment of recurrent bulbar urethral strictures. Early efficacy results are encouraging and 
support further followup of these men through five years, as well as further investigation with a randomized trial.

\section{Introduction}

Approximately $0.6 \%$ of men experience a urethral stricture in their lifetime. ${ }^{1}$ Treatment options include dilation (rigid or balloon), direct visual internal urethrotomy (DVIU), implanted stent, and urethroplasty. Dilation and DVIU comprise $95 \%$ of urethral stricture treatments as they are minimally invasive, low cost, and can be performed by any urologist; but recurrence rates are high. ${ }^{2}$ A recent review demonstrated a $90 \%$ lifetime recurrence rate, even for first time dilations, and near $100 \%$ for repeat dilations. ${ }^{3}$ Dilation and DVIU have similar outcomes, whereas urethroplasty has the highest rate of success. ${ }^{4,5,6,7}$ Steroid or mitomycin C (MMC) injection have been used as an adjuvant to endoscopic treatment, but results have been mixed. $8,9,10,11$

The Optilume Drug Coated Balloon (DCB; Urotronic, Plymouth, MN) combines dilation with circumferential delivery of paclitaxel. Paclitxel is an anti-fibrotic, anti-proliferative drug that is used as a coating in minimally invasive vascular applications to prevent restenosis. ${ }^{12,13,14}$ ROBUST I is a prospective study evaluating the safety and preliminary efficacy of DCB for urethral stricture.

\section{Methods}

\section{Study design and participants}

This was a single arm, prospective, open-label study, conducted under a common protocol at four Latin American centers. Eligible patients were men $\geq 18$ years, with a single bulbar urethral stricture $<12 \mathrm{Fr}$, and $\leq 2.0 \mathrm{~cm}$ long on urethrogram. Patients were included if they had undergone 1 to 4 prior endoscopic treatments (none within 3 months prior to enrollment), had an International Prostate Symptom Score (IPSS) $\geq 13$, and maximum flow rate $<10 \mathrm{ml} / \mathrm{sec}$. Patients were excluded for prior urethroplasty, radical prostatectomy, lichen sclerosus, penile prosthesis or artificial urinary sphincter, pelvic radiation, urinary stone passage in previous 6 months, chronic kidney disease or serum creatinine $>2 \mathrm{mg} / \mathrm{dL}$, intradetrusor onabotulinum toxin A injection in within 12 months of study entry, neurogenic bladder, bladder or prostate cancer in previous 5 years, or active non-genitourinary cancer.

\section{Procedures}

After a baseline urethrogram, strictures were pre-treated with an uncoated balloon and/or DVIU until lumen diameter increased by $50 \%$. Although the DCB is intended to be used without pretreatment, we performed pre-treatment in this first-in-man study 1) to ensure the DCB could cross the stricture without disrupting the drug coating, and 2) to prevent double dosing patients 
with a lumen $<20 \mathrm{Fr}$ after the first DCB treatment. The DCB was inflated to the rated burst pressure and held for $>=5$ minutes. The DCB was $3 \mathrm{~cm}$ in length and $24 \mathrm{~F}$ (other sizes are now available). Follow-up was at 5, 14, 90, 180, and 365 days; annual follow-up is planned for 5 years. IPSS was administered before intervention and at each follow-up visit. Cystoscopy was performed at 180- and 365-days post-procedure. Due to the variety in size of cystoscopes used (15F-20F), if the cystoscope could not be passed beyond the narrowing but a 14F catheter could be passed atraumatically, this was considered an anatomic success.

\section{Primary safety endpoint}

The primary safety endpoint was the rate of treatment-related urinary severe adverse events (SAEs), defined as urethral fistula formation, de novo urinary retention $>14$ days post-treatment, de novo stress incontinence ( $>1 \mathrm{pad} /$ day) at 90 days post-treatment, or urethral rupture.

\section{Efficacy endpoint}

The efficacy endpoint was defined as 1-year anatomic success without retreatment, regardless of symptoms or flow rate. Failure was defined as anatomic failure or retreatment; additionally, any subject who exited the study prior to cystoscopic evaluation with IPSS $\geq 11$ was considered a failure. Subjects were right-censored when lost to follow-up if IPSS $<11$ at exit, or IPSS $\geq 11$ without recurrence on cystoscopy.

\section{Secondary endpoints}

Secondary endpoints included: 1) IPSS; 2) sexual function, using the "Overall Satisfaction" question of the International Index of Erectile Function; $\left.{ }^{15} 3\right)$ Maximum urinary flow rate ( $(\mathrm{max})$; 4) post-void residual urine volume (PVR); 5) concentration of paclitaxel in the blood, urine, and semen; and 6) pain (Visual Analog Scale, VAS). ${ }^{16}$

\section{Data analysis}

Baseline characteristics and the primary safety endpoint were tabulated using descriptive analysis. The number and percentage of subjects experiencing at least one device-related SAE were presented for this endpoint, along with the $95 \%$ confidence interval. The preliminary efficacy endpoint was met if the lower limit of the one-sided $95 \%$ confidence interval for anatomic success exceeded the reference success rate. The reference rate was drawn from the Steenkamp and Heyns randomized trial of DVIU vs. dilation. ${ }^{4}$ This reference success rate varies with the number of prior treatments: $65 \%$ at one year for men with $0-1$ prior endoscopic procedures and $10 \%$ for men with 2 prior endoscopic procedures. ${ }^{4}$ It was unclear a priori how many prior dilations our cohort would have (inclusion criteria were 1 to 3 prior endoscopic procedures), so we targeted enrollment based on a power calculation using the more stringent $65 \%$ success rate. 


\section{Results}

\section{Patients}

Between November 29, 2016 and September 9, 2017, 53 patients were enrolled and treated with the DCB. Average age was 50.7 years (range 22-81) and the majority (83\%) were Hispanic/Latino (Table 1). Stricture etiology was traumatic (51\%), iatrogenic $(45 \%)$ or idiopathic (4\%). All strictures were bulbar, with an average length of $0.9 \mathrm{~cm}$. Mean stricture narrowing was $<9 \mathrm{~F}$ and the mean number of endoscopic procedures prior to enrollment was 1.7. Some patients performed intermittent dilation independently, but only the physician administered procedures were recorded. Seven patients $(13.2 \%)$ had a suprapubic catheter at the time of enrollment. Pre-treatment immediately prior to DCB was accomplished with an uncoated balloon in $58 \%$, DVIU in $15 \%$, or uncoated balloon and DVIU in $26 \%$.

\section{Primary safety and preliminary efficacy Eendpoints}

There were no treatment-related urinary SAEs at 90 days post-procedure. There were two SAEs (myocardial infarction and abdominal pain) at 6 months and 12 months post-procedure respectively, but unrelated to the procedure. In total, there were 52 adverse events, most commonly urinary tract infection (15\%), fever (12\%), acute urinary retention $(8 \%)$, headache $(8 \%)$, and dysuria $(6 \%)$. The majority were classified as mild $(58 \%)$ or moderate $(38 \%)$ according to the Common Terminology Criteria for Adverse Events, and 25\% were categorized as "possibly," "probably," or "definitely" related to the procedure (Figure 1).

Anatomic success was achieved in 32/46 (70\%; 95\% CI, 54-82\%) at 12 months (Table 2). The 14 failures included 7 cystoscopic recurrences ( 6 at 6 months, 1 at 12 months), 5 retreatments (4 at 3 months, 1 at 12 months) and 2 who exited the study with IPSS $>11$ prior to cystoscopy (both at 3 months). Of the 6 men with cystoscopic recurrence at 6 months, 1 underwent retreatment, 1 exited the study and 4 were observed. IPSS in those who were observed remained $\leq 11$ at both 6 and 12 months. Anatomic success rates did not vary significantly based on the number of prior endoscopic treatments: 77\% (23/30) among men with 1 prior treatment, $62 \%(8 / 13)$ with 2 treatments, $87 \%(7 / 8)$ with 3 treatments, and $50 \%(1 / 2)$ in men with 4 previous treatments $(\mathrm{p}=0.47)$. Neither did success rates vary by stricture etiology: $67 \%(18 / 27)$ in traumatic strictures, (83\%) 20/24 in iatrogenic strictures, and (50\%) 1/2 in idiopathic strictures $(\mathrm{p}=0.30)$.

\section{Secondary endpoints}

Baseline IPSS ranged from 15 to 34 with a mean of $25.2( \pm 4.5)$, and IPSS-QOL ranged from 2 to 6 with a mean of $4.9( \pm 0.9)$. At 90 days post-procedure, mean IPSS and IPSS-QOL were 6.1 $( \pm 7.6)$ and $0.8( \pm 1.3)$ respectively. At one year, there was a statistically significant improvement in mean IPSS $(4.9 \pm 5.6)$ and IPSS-QOL $(0.8 \pm 1.1)$ compared to baseline $(\mathrm{p}<0.001)$ (Table 3). Urinary symptom resolution, represented by IPSS $<11$ without retreatment, occurred in $79 \%$ 
(38/48) at one year. Of note, although the retreatment outcome was definitive, urinary symptoms fluctuated; there were 7 men who had IPSS $\geq 11$ at 3 or 6 months who then had IPSS $<11$ at one year without retreatment. Mean IIEF-satisfaction scores were $6.5( \pm 2.6)$ at baseline and 7.8 $( \pm 2.6)$ one year post-treatment (Table 3). Mean $\mathrm{Q}_{\max }$ improved from $5.0 \mathrm{ml} / \mathrm{sec}$ (baseline) to 23.6, 24.2, 22.2, 20.5 and $19.5 \mathrm{ml} / \mathrm{sec}$ at the 14, 30, 90, 180, and 365-day follow-ups. Additionally, the average PVR decreased from $141.0 \mathrm{ml}$ (baseline) to $27.3 \mathrm{ml}$ and $26.7 \mathrm{ml}$ at the 180 and 365-day follow-ups respectively (Table 3).

Urinary paclitaxel concentration was $184.3 \mathrm{ng} / \mathrm{mL} \pm 179.1 \mathrm{ng} / \mathrm{ml}$ immediately postprocedure $(\mathrm{n}=52)$ and $2.6 \mathrm{ng} / \mathrm{mL} \pm 4.8 \mathrm{ng} / \mathrm{mL}$ at 5 days $(\mathrm{n}=21)$. Plasma paclitaxel concentration was very low as it was near the limit of quantification immediately post-procedure (Low $=0.1$ $\mathrm{ng} / \mathrm{mL})$. Semen paclitaxel concentration was low: $2.5 \mathrm{ng} / \mathrm{mL} \pm 2.9(\mathrm{n}=31)$ at 14 days and $1.0 \pm$ $1.6 \mathrm{ng} / \mathrm{mL}(\mathrm{n}=24)$ at 30 days post procedure. Most patients experienced only minor preprocedure pain associated with their stricture disease, with a mean VAS score of $2.9( \pm 2.87)$. Mean VAS Scores decreased to $0.6( \pm 1.0)$ and $0.9( \pm 1.9)$ at 14 and 30 days (Table 3).

\section{Discussion}

The ROBUST I trial is a multicenter, single-arm, open-label study investigating the safety and efficacy of the Optilume DCB among male patients with a single bulbar recurrent urethral stricture. There were no treatment-related SAEs. The majority of side effects were mild or moderate in severity; the most common was urinary tract infection. When paclitaxel is used for chemotherapy, drug-related side effects include neurotoxicity and myelosuppression; ${ }^{17}$ these were not seen in the current study. Paclitaxel urine concentrations immediately post-procedure were about six times lower than in chemotherapy patients and dropped significantly by 5 days; serum levels were also very low. ${ }^{18}$

This study will eventually yield 5-year efficacy outcomes; herein we report preliminary 1 -year success of $70 \%$ with a $95 \%$ CI of $54-82 \%$. The $95 \%$ CI did not exceed the reference $65 \%$ success rate for men with 0-1 prior dilations in the Steenkamp and Heyns study, but did exceed the reference $10 \%$ rate for men with 2 prior dilations. ${ }^{3}$

Secondary outcome measures demonstrated an improvement in urinary symptoms, urinary quality of life, pain scores, and uroflowmetry- specifically $\mathrm{Q}_{\max }$, and PVR. Sexual function was not significantly affected by DCB.

Although this is the first study conducted using a paclitaxel-DCB for urethral strictures, several other studies have investigated other drugs in conjunction with mechanical dilation. A recent study demonstrated $75 \%$ patency at 2 years following DVIU with MMC injection and self-dilation $;{ }^{19}$ but, significant adverse effects have been reported after MMC injection into urinary mucosa, including osteitis pubis, urethral fistula formation, and tissue necrosis. ${ }^{11}$ Outcomes with urethral triamcinolone as an adjuvant vary widely between studies. ${ }^{20,21}$ The Optilume DCB may offer advantages compared to these other adjuvants. First, as a hydrophobic 
drug it absorbs easily into the target tissue avoiding immediate washout. Second, the half-life of paclitaxel is measured in days whereas the half-life of MMC is hours. This allows paclitaxel to be present during the inflammatory, proliferation and remodeling stages of wound healing. Third, the paclitaxel dosing is tightly controlled by the proprietary DCB coating process, avoiding the risks of overdosing with manual injection. In Good Laboratory Practice Animal study data acquired prior to study initiation, urethral tissue concentration of paclitaxel drops $73 \%$ after 7 days and remains quantifiable in most subjects through 28 days. Fourth, paclitaxel is circumferentially delivered topically to the urothelium, reducing the risk of periurethral dosing that can occur with deep injections.

Among the limitations, there was no control arm in this early phase study. Further, we excluded penile strictures, bladder neck contractures, patients with previous pelvic radiotherapy, and patients with a history of lichen sclerosus; the DCB may perform worse in these strictures which are known to have a higher risk of recurrence. Furthermore, the 12-month follow-up does not capture patients with delayed stricture recurrence, however data suggests the mean time from endoscopic treatment to stricture recurrence is 6-12 months. ${ }^{22}$ We will report 5-year results as they become available. There were patients in our cohort who performed self-dilation, but only physician-administered dilations were recorded; it is unknown how this affected stricture recurrence. Future results without pretreatment may differ from those seen in this study where all patients were pre-treated with DIVU or dilation.

\section{Conclusions}

The Optilume DCB is safe; early efficacy results are encouraging and support further follow-up of these men through 5 years as well as further investigation with a randomized trial.

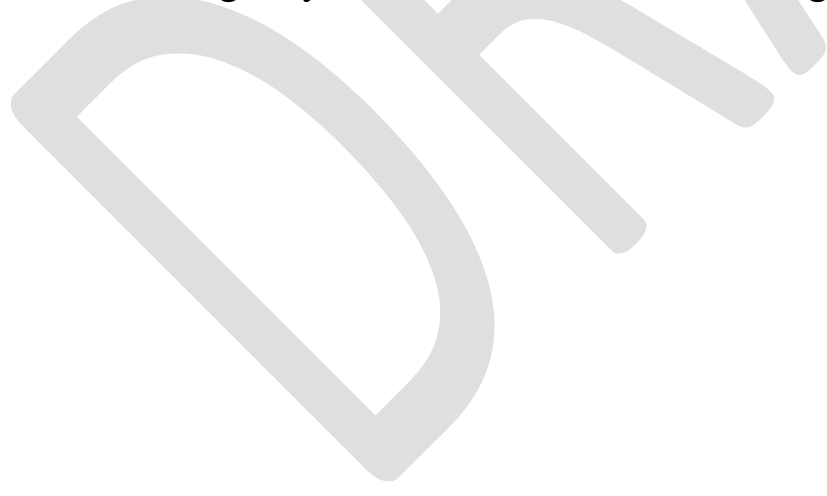




\section{References}

${ }^{1}$ Santucci RA, Joyce GF, Wise M. Male urethral stricture disease. J Urol 2007;177:1667-74.

${ }^{2}$ Liu JS, Hofer MD, Oberlin DT, et al. Practice patterns in the treatment of urethral stricture among American urologists: A paradigm change? Urology 2015;86:830-4.

${ }^{3}$ Shaw NM, Venkatesan K. Endoscopic management of urethral structure: Review and practice algorithm for management of male urethral stricture disease. Curr Urol Rep 2018;19:19.

${ }^{4}$ Steenkamp JW, Heyns CF, de Kock ML. Internal urethrotomy versus dilation as treatment for male urethral strictures: a prospective, randomized comparison. J Urol 1997;157:98-101.

${ }^{5}$ Albers P, Fichtner J, Brühl P, et al. Long-term results of internal urethrotomy. J Urol 1996; 156:1611.

${ }^{6}$ Charbit L, Mersel A, Beurton D, et al. 5-year treatment results of urethral stenosis using internal urethrotomy in adults. Ann Urology 1990;24:66.

${ }^{7}$ Jordan GH, Rourke KF. Primary urethral reconstruction: the cost minimized approach to the bulbous urethral stricture. J Urol 2005;173:1206.

${ }^{8}$ Zhang K, Qi E, Zhang Y, et al. Efficacy and safety of local steroids for urethra structures: a systematic review and meta-analysis. J Endourol 2014;28:962-8.

${ }^{9}$ Mazdak H, Izadpanahi MH, Ghalamka A, et al. Internal urethrotomy and intraurethral submucosal injection of triamcinolone in short bulbar urethral strictures. Int Urol Nephrol 2010;41:565-8.

${ }^{10}$ Vanni AJ, Zinman LN, Buckley JC. Radial urethrotomy and intralesional mitomycin C for the management of recurrent bladder neck contractures. J Urol 2011;186:156-60.

${ }^{11}$ Redshaw JD, Broghammer JA, Smith TG, et al. Intralesional injection of mitomycin C at transurethral incision of bladder neck contracture may offer limited benefit: TURNS Study Group. J Urol 2015;193:587-92.

12 Käsmann L, Manig L, Janssen S, Rades D. Chemoradiation including paclitaxel for locally recurrent muscle-invasive bladder cancer in elderly patients. In Vivo 2017;31: 239-42.

${ }^{13}$ Herten M, Torsello GB, Stahlhoff S. Critical appraisal of paclitaxel balloon angioplasty for femoral-popliteal arterial disease. Vasc Health Risk Manag 2016;12:341-56.

${ }^{14}$ Habib A, Finn AV. Antiproliferative drugs for restenosis prevention. Interv Cardiol Clin 2016;5:321-29.

${ }^{15}$ Rosen RC, Riley A, Wagner G, et al. The international index of erectile function (IIEF): a multidimensional scale for assessment of erectile dysfunction. Urology 1997;49:822-30.

${ }^{16}$ Couper M, Tourangeau R, Conrad F, et al. Evaluating the effectiveness of visual analog scales: A web experiment. Soc Sci Comput Rev 2006;24:227-45.

${ }^{17}$ Marupundi NI, Han JE, Li KW, et al. Paclitaxel: a review of adverse toxicities and novel delivery strategies. Expert Opin Drug Saf 2007;6:609-21.

${ }^{18}$ Rowinsky EK, Cazenave LA, Donehower RC. Taxol: a novel investigational antimicrotubule agent. J Natl Cancer Inst 1990;82:1247-59.

${ }^{19}$ Farrell MR, Lawrenz CW, Levine LA. Internal urethrotomy with intralesional mitomycin C: an effective option for endoscopic management of recurrent bulbar and bulbomembranous urethral strictures. Urology 2017;110:S223. 
${ }^{20}$ Ergün O, Güzel A, Armağan A, et al. A prospective, randomized trial to evaluate the efficacy of clean intermittent catheterization versus triamcinolone ointment and contractubec ointment of catheter following internal urethrotomy: long-term results. Int Urol Nephrol 2015;47:909-13.

${ }^{21}$ Kumar S, Kishore L, Sharma AP, et al. Efficacy of holmium laser urethrotomy and intralesional injection of Santosh PGI tetra-inject (triamcinolone, mitomycin c, hyaluronidase and n-acetyl cysteine) on the outcome of urethral strictures. Cent Eur J Urol 2015;68:462-5. ${ }^{22}$ Heyns CF, Steenkamp JW, Kock ML, et al. Treatment of male urethral strictures: is repeated dilation or internal urethrotomy useful? J Urol 1998;160:356-8. 


\section{Figures and Tables}

Fig. 1. Adverse event, relation to treatment, and severity. Severity was determined using the Common Terminology Criteria for Adverse Events (CTCAE v4.0) Severity Scale.

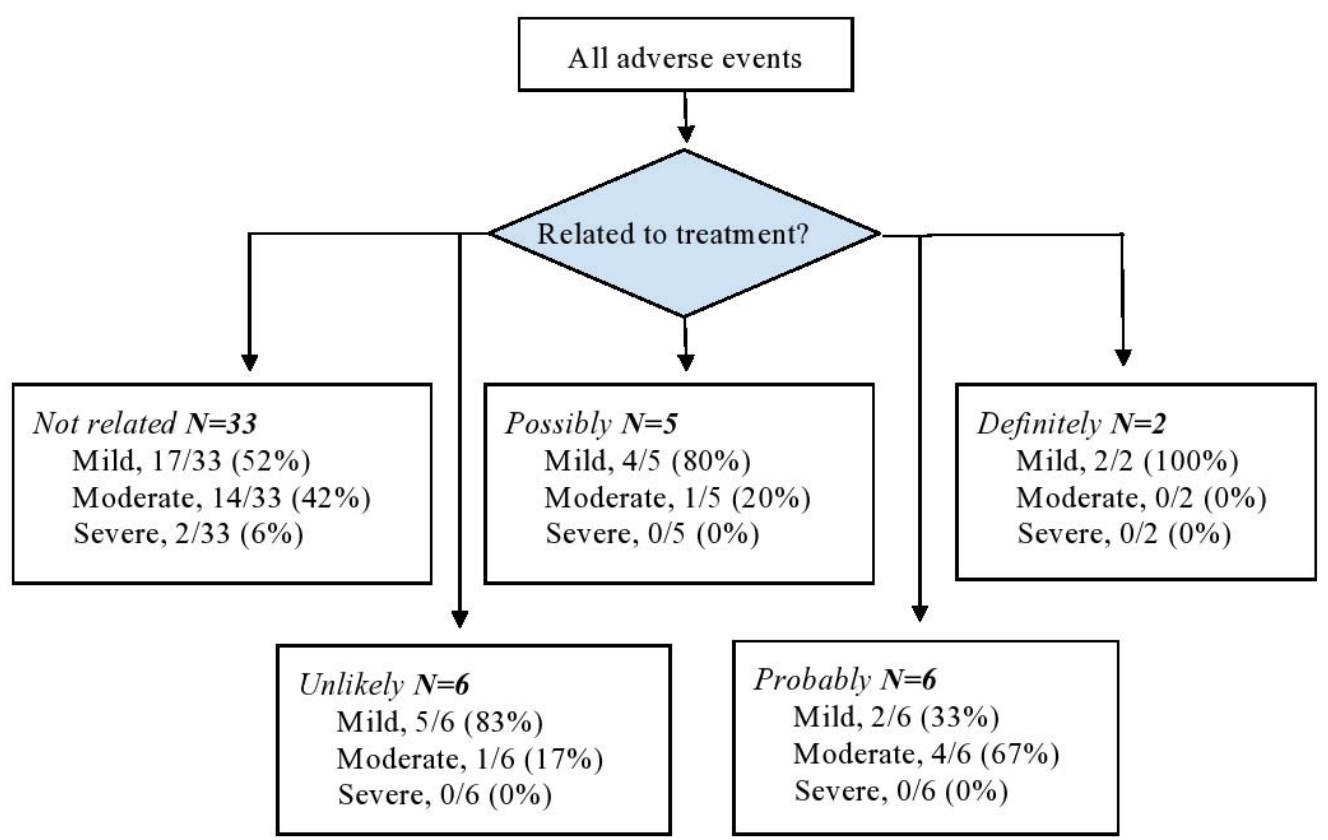




\section{Table 1. Patient demographics and urologic medical history}

\begin{tabular}{|l|c|}
\hline Variables & $\mathbf{N}=\mathbf{5 3}$ \\
\hline Patient demographics & \\
\hline Age (years) & \\
Mean \pm SD & $50.7 \pm 15.47$ \\
Range & $22.0-81.0$ \\
Median & 50.0 \\
\hline Male gender, n (\%) & $53(100.0 \%)$ \\
\hline Race of subjects, $\mathrm{n}(\%)$ & \\
Black or African Origin & $8(15.1 \%)$ \\
Hispanic or Latino & $44(83.0 \%)$ \\
Other & $1(1.9 \%)$ \\
\hline Suprapubic catheter at baseline & $7(13.2 \%)$ \\
\hline Stricture etiology, n (\%) & \\
Iatrogenic & $24(45.3 \%)$ \\
Idiopathic & $2(3.8 \%)$ \\
Traumatic & $27(50.9 \%)$ \\
\hline Stricture measurements, mean \pm SD & \\
Stricture length (mm) & $9.00 \pm 5.20$ \\
Urethral diameter at stricture (mm) & $2.47 \pm 1.97$ \\
Urethral diameter at area healthy tissue (mm) & $10.2 \pm 3.62$ \\
\hline Pre-treatment & $31(58 \%)$ \\
Uncoated balloon & $8(15 \%)$ \\
DVIU & $14(26 \%)$ \\
Uncoated balloon + DVIU & \\
Number of previous endoscopic treatments, $\mathrm{n}(\%)$ & $30(57 \%)$ \\
1 & $13(25 \%)$ \\
2 & $8(15 \%)$ \\
3 & $2(4 \%)$ \\
4 &
\end{tabular}

DVIU: direct visual internal urethrotomy; SD: standard deviation. 


\begin{tabular}{|l|c|c|c|c|}
\hline \multicolumn{1}{|c|}{ Table 2. Anatomic success rates over time } \\
\hline \multirow{2}{*}{ Outcomes } & $\mathbf{0}$ & $\mathbf{3}$ & $\mathbf{6}$ & $\mathbf{1 2}$ \\
\cline { 2 - 5 } & 53 & 45 & 39 & 32 \\
\hline Success & 0 & 6 & 12 & 14 \\
\hline Fail - cumulative & 0 & 2 & 2 & 7 \\
\hline Censor - cumulative & 53 & 51 & 51 & 46 \\
\hline $\begin{array}{l}\text { Number remaining } \\
\text { for analysis (total - } \\
\text { censor) }\end{array}$ & & & 76 & 70 \\
\hline Success (\%) & 100 & 88 & & \\
\hline
\end{tabular}

Failure defined as: inability to pass a cystoscope and a $14 \mathrm{~F}$ catheter $(\mathrm{n}=7)$, retreatment $(\mathrm{n}=5)$, exit with International Prostate Symptom Score (IPSS) $>11$ but no cystoscopy performed $(n=2)$. Success defined as: Normal cystoscopy or $14 \mathrm{~F}$ catheter test without retreatment, regardless of symptoms (symptoms without stricture is presumed to be benign prostatic hyperplasia). Censor: Exit/lost to followup without symptoms and normal cystoscopy or 14F catheter test 
Table 3. Results of secondary endpoints

\begin{tabular}{|c|c|c|c|c|c|c|}
\hline Category & Baseline & 14 days & 30 days & 90 days & 180 days & 365 days \\
\hline $\begin{array}{l}\text { IPSS score } \\
\text { Mean } \pm \text { SD } \\
\mathrm{n} \\
\text { Range } \\
\text { Median } \\
\end{array}$ & $\begin{array}{c}25.2 \pm 4.46 \\
53 \\
15.0-34.0 \\
26.0 \\
\end{array}$ & $\begin{array}{c}5.1 \pm 5.45 \\
51 \\
0.0-33.0 \\
4.0 \\
\end{array}$ & $\begin{array}{c}4.3 \pm 5.95 \\
51 \\
0.0-34.0 \\
2.0 \\
\end{array}$ & $\begin{array}{c}6.1 \pm 7.63 \\
51 \\
0.0-30.0 \\
3.0 \\
\end{array}$ & $\begin{array}{c}4.8 \pm 6.41 \\
47 \\
0.0-34.0 \\
3.0 \\
\end{array}$ & $\begin{array}{c}\mathrm{a} 4.9 \pm 5.63 \\
42 \\
0.0-31.0 \\
3.5 \\
\end{array}$ \\
\hline $\begin{array}{l}\text { IPSS QOL } \\
\text { Mean } \pm \text { SD } \\
\mathrm{n} \\
\text { Range } \\
\text { Median } \\
\end{array}$ & $\begin{array}{c}4.9 \pm 0.86 \\
53 \\
2.0-6.0 \\
5.0\end{array}$ & $\begin{array}{c}0.8 \pm 0.94 \\
51 \\
0.0-5.0 \\
1.0\end{array}$ & $\begin{array}{c}0.7 \pm 1.05 \\
51 \\
0.0-6.0 \\
0.0\end{array}$ & $\begin{array}{c}0.8 \pm 1.32 \\
51 \\
0.0-5.0 \\
0.0\end{array}$ & $\begin{array}{c}0.7 \pm 1.02 \\
47 \\
0.0-4.0 \\
0.0\end{array}$ & $\begin{array}{c}{ }^{\mathrm{a}} 0.8 \pm 1.06 \\
42 \\
0.0-4.0 \\
0.0\end{array}$ \\
\hline $\begin{array}{l}\text { IIEF: Overall } \\
\text { satisfaction } \\
\text { Mean } \pm \mathrm{S} D \\
\mathrm{n} \\
\text { Range } \\
\text { Median } \\
\end{array}$ & $\begin{array}{c}6.5 \pm 2.62 \\
53 \\
2.0-10.0 \\
6.0\end{array}$ & 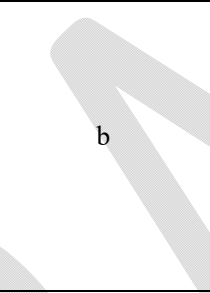 & $\begin{array}{c}7.1 \pm 2.49 \\
51 \\
2.0-10.0 \\
8.0\end{array}$ & $\begin{array}{c}7.9 \pm 2.53 \\
51 \\
2.0-10.0 \\
8.0\end{array}$ & $\begin{array}{c}7.6 \pm 2.82 \\
47 \\
2.0-10.0 \\
8.0\end{array}$ & $\begin{array}{c}7.8 \pm 2.6242 \\
2.0-10.0 \\
8.5\end{array}$ \\
\hline $\begin{array}{l}\text { Qmax }(\mathrm{mL} / \mathrm{sec}) \\
\text { Mean } \pm \mathrm{SD} \\
\mathrm{n} \\
\text { Range } \\
\text { Median } \\
\end{array}$ & $\begin{array}{c}5.0 \pm 2.56 \\
46 \\
0.0-10.0 \\
5.0 \\
\end{array}$ & $\begin{array}{c}23.6 \pm 12.63 \\
51 \\
5.0-52.0 \\
21.3 \\
\end{array}$ & $\begin{array}{c}24.2 \pm 14.15 \\
50 \\
5.9-67.3 \\
20.5 \\
\end{array}$ & $\begin{array}{c}22.2 \pm 12.49 \\
51 \\
2.0-50.0 \\
19.6 \\
\end{array}$ & $\begin{array}{c}20.5 \pm 10.36 \\
47 \\
3.0-50.0 \\
19.0 \\
\end{array}$ & $\begin{array}{c}\mathrm{a} 19.5 \pm 9.96 \\
42 \\
4.9-40.5 \\
18.0 \\
\end{array}$ \\
\hline $\begin{array}{l}\text { PVR }(\mathrm{mL}) \\
\text { Mean } \pm \mathrm{SD} \\
\mathrm{n} \\
\text { Range } \\
\text { Median } \\
\end{array}$ & $\begin{array}{c}141.4 \pm 105.05 \\
43 \\
0.0-462.0 \\
128.0 \\
\end{array}$ & $\begin{array}{c}32.7 \pm 33.06 \\
49 \\
0.0-132.0 \\
24.0\end{array}$ & $\begin{array}{c}33.0 \pm 33.51 \\
49 \\
0.0-181.9 \\
25.0\end{array}$ & $\begin{array}{c}36.1 \pm 36.24 \\
51 \\
0.0-150.0 \\
26.0\end{array}$ & $\begin{array}{c}27.3 \pm 41.68 \\
47 \\
0.0-200.0 \\
13.0\end{array}$ & $\begin{array}{c}26.79 \pm 33.10 \\
42 \\
0.0-163.0 \\
19.0\end{array}$ \\
\hline $\begin{array}{l}\text { VAS pain score } \\
\text { Mean } \pm \mathrm{SD} \\
\mathrm{n} \\
\text { Range } \\
\text { Median }\end{array}$ & $\begin{array}{c}2.9 \pm 2.87 \\
53 \\
0.0-10.0 \\
3.0\end{array}$ & $\begin{array}{c}0.6 \pm 0.98 \\
51 \\
0.0-4.0 \\
0.0\end{array}$ & $\begin{array}{c}0.9 \pm 1.87 \\
51 \\
0.0-8.0 \\
0.0\end{array}$ & & & \\
\hline
\end{tabular}

${ }^{a}$ Comparing to the baseline value, $\mathrm{p}<0.001$. ${ }^{\mathrm{b}}$ The patients were asked to refrain from sexual intercourse until day 30; therefore, the relevant comparison of IIEF scores is at baseline, 30 days, and beyond.

IIEF: International Index of Erectile Function; IPSS: International Prostate Symptom Score; SD: standard deviation; PVR: post-void residual; Qmax: maximum urinary flow rate; QOL: quality of life; VAS: Visual Analog Scale. 